\title{
Detailed chemical composition and functional properties of Ammodaucus leucotrichus Cross. \& Dur. and Moringa oleifera Lamarck
}

\author{
Borhane E.C. Ziani ${ }^{\mathrm{a}, \mathrm{b}, \mathrm{c}}$, Wahiba Rached ${ }^{\mathrm{a}, \mathrm{d}}$, Khaldoun Bachari ${ }^{\mathrm{b}}$, Maria José Alves $^{\mathrm{a}}$, \\ Ricardo C. Calhelha ${ }^{\mathrm{a}}$, Lillian Barros ${ }^{\mathrm{a}, *}$, Isabel C.F.R. Ferreira ${ }^{\mathrm{a}, *}$ \\ ${ }^{a}$ Centro de Investigacão de Montanha (CIMO), Instituto Politécnico de Bragança, Campus de Santa Apolónia, 5300-253 Bragança, Portugal \\ ${ }^{\mathrm{b}}$ Centre de Recherche Scientifique et Technique en Analyses Physico-Chimiques CRAPC-Bouismail-Tipaza, Algeria \\ ${ }^{\mathrm{c}}$ Département de Technologie Alimentaire et Nutrition Humaine, Ecole Nationale Supérieure Agronomique ENSA-Alger, Algeria \\ ${ }^{\mathrm{d}}$ Département de Biologie, Faculté des Sciences de la Nature et de la Vie, Université de Mostaganem 1, BP 188/227, Mostaganem 2700, Algeria
}

\section{A R T I C L E I N F O}

\section{Keywords:}

Ammodaucus leucotrichus

Moringa oleifera

Nutritional value

Phenolic compounds

Cytotoxicity

Anti-inflammatory

Antibacterial activity

\begin{abstract}
A B S T R A C T
Edible Ammodaucus leucotrichus Cross. \& Dur. and Moringa oleifera Lamarck are largely used in the Algerian Sahara. In this context, soluble sugars, fatty acids, organic acids, and tocopherols were characterized. Decoctions and hydroethanolic extracts were studied regarding their phenolic compounds by HPLC-DAD-ESI/MSn, and invitro cytotoxic, anti-inflammatory, and antibacterial activities were evaluated. Results indicate high contents of carbohydrates (glucose and sucrose) and significant levels of protein and mineral were recorded for both plants. Malic acid was the major organic acid alongside with $\alpha$-tocopherol, while PUFA was predominant in $M$. oleifera and MUFA in A. leucotrichus. Flavonoid derivatives were the most abundant group, being luteolin-O-(malonylglucoside) the main compound in $A$. leucotrichus and quercetin-3-O-(6"-malonyl-glucoside) and 3-O-caffeoylquininc acid the major molecules in M. oleifera. Extracts exhibited significant cytotoxicity on Hela and MCF-7 cell lines. The anti-inflammatory activity was also higher in the hydroethanolic extracts, which also revealed the highest antibacterial effects, especially for Gram-positive bacteria.
\end{abstract}

\section{Introduction}

The abundance of bioactive molecules in plants is an important asset in the screening of new agents for therapeutic and agro-food purposes (Shahidi \& Ambigaipalan, 2015). This may also elicit a long range of different physiological effects, due to their richness and varied nutritional constituents, deriving essentially from the primary metabolism, such as sugars, lipids, proteins, and ash. These metabolites are helpful for many biological and functional needs (Pires, Dias, Barros, \& Ferreira, 2017), either enhancing the nutritional and organoleptic properties of food products (Shahidi \& Ambigaipalan, 2015), or working alongside with the secondary bioactive metabolites, such as phenolic compounds. These molecules are applied due to their several functional properties, including anti-proliferative, anti-inflammatory (Sobral et al., 2016), as also antimicrobial (Vadhana, Singh, Bharadwaj, \& Singh, 2015).

The Algerian Sahara has a rich and prestigious heritage of plantbased medicines (Benarba, 2016) and many species are used in traditional phytotherapy, which contributed for the development of new therapeutic pathways (Benarba, 2016; Ziani et al., 2015). Ammodaucus leucotrichus Coss. \& Dur. (Apiaceae) is an endemic plant in North Africa and is widely used in traditional medicine, especially in the southern Algerian Sahara and Tassili regions (Louail et al., 2016). Leaves and seeds of this plant are consumed in the form of infusions and/or decoctions for several therapeutic cases, such as liver and digestive system ailments, gastroenteritis, diabetes, as also for blood pressure and chest pain (Halla, Boucherit, Boucherit-otmani, Zohra, \& Rahmani, 2018; Louail et al., 2016). The fruits are often used as a spice during culinary preparation, and leaves are used as a flavoring herbal in teas (Halla et al., 2018; Louail et al., 2016). Nevertheless, most phytochemical and biological studies on A. leucotrichus are related to the volatile compounds from the essential oils (Gherraf et al., 2017; Halla et al., 2018), and few scientific studies have been conducted towards the phenolic compounds and their functional properties. According to a recent study conducted by Halla, Heleno, Costa, Fernandes, Calhelha, Boucherit, Rodrigues, Ferreira, and Barreiro (2018) using colorimetric reactions, flavonoids, condensed and hydrolysable tannins, coumarins, alkaloids, and terpenoids were found in the Algerian A. leucotrichus aqueous extract obtained by decoction and in the hydromethanolic extract. El Haci, Mazari, Gherib, and Atik Bekkara (2018) reported moderate

\footnotetext{
* Corresponding authors.

E-mail addresses: lillian@ipb.pt (L. Barros), iferreira@ipb.pt (I.C.F.R. Ferreira).
} 
levels of total phenols and flavonoids in the polar organic extracts (ethanolic, methanolic and acetone extracts) of A. leucotrichus from Bechar-Algeria. However, to the author's best knowledge no reports regarding the nutritional composition, individual phenolic compounds profile, cytotoxicity, anti-inflammatory, and antibacterial activity of this plant has been published until now.

Moringa oleifera Lamarck (Moringaceae) is a South Asian tree, commonly known as 'drumstick tree' or 'horseradish tree' (Anwar, Latif, Ashraf, \& Gilani, 2007). Recently, it has attracted a lot of attention due to its nutritional value, as also health benefits (David et al., 2017) such as, inflammation treatments, diabetes, gastro-intestinal and infectious diseases along with cardiovascular, hematological, and hepatorenal disorders (David et al., 2017; Gopalakrishnan, Doriya, \& Santhosh, 2016). The reason why it has been introduced in many parts of the world, including Algeria, where it is cultivated in some Saharan areas (Bachar and tamanrasset), is mainly due to its food security and nutritional proposes (Boukandoul, Casal, Cruz, Pinho, \& Zaidi, 2017). Edible leaves and seeds of $M$. oleifera (eaten fresh, powdered or cooked) contain a varied profile of many nutrients, such as essential sulfur amino acids, protein and minerals (Maryann, Lord, Uchechukwu, \& Chibuike, 2018). It is also a renewable source of polyunsaturated fatty acids (PUFA) (Stadtlander \& Becker, 2017), tocopherols ( $\gamma$ and $\alpha$ isoforms) (Sánchez-Machado, Lopez-Cervantes, \& Rios Vazquez, 2006), $\beta$ carotene, and other vitamins, as well as phenolic compounds (Gopalakrishnan et al., 2016). Phytochemicals have been isolated from different parts of $M$. oleifera, such as zeatin, quercetin, sitosterol, caffeoylquinic acid, kaempferol, tannins, terpenoids, saponins, anthraquinones, and alkaloids (Nouman, Anwar, Gull, Newton, \& Rosa, 2016; Upadhyay, Yadav, Mishra, Sharma, \& Purohit, 2015). Anti-cancerous agents, like glucosinolates, isothiocyanates, glycoside compounds, and glycerol-1-9-octadecanoate have been reported to exercise an effective action on cancer cell lines, during the different stages of cancer evolution (Edwinanto, Septiadi, Nurfazriah, Anastasya, \& Pranata, 2018; Tiloke, Phulukdaree, \& Chuturgoon, 2013). Leaves of M. oleifera have a low caloric value and can be used in a healthy diet. The fruits (pods) are fibrous and are valuable to treat digestive problems and thwart colon cancer (Moyo, Masika, Hugo, \& Muchenje, 2011).

Due to the multiple traditional uses of these species by the Saharan population in Algeria, but also its usage around the world, the aim of the present study was to determine the nutritional value and chemical composition regarding minerals, free sugars, organic acids, fatty acids, and tocopherols. Moreover, the biological potential as anti-proliferative, anti-inflammatory and antibacterial agents of the decoction and hydroethanolic extracts of both plant species was also studied. Furthermore, the targeted functional properties were related to their phenolic profile determined by HPLC-DAD-ESI/MSn.

\section{Materiel and methods}

\subsection{Plant material}

Aerial parts of spontaneous Ammodaucus leucotrichus Cross. \& Dur. (locally named as "Kemoun msawef") and leaves of the cultivated Moringa oleifera Lamarck were harvested in September 2017, from the desert areas of south Algeria, such as Tamanrasset (Coordinates: $22^{\circ} 47^{\prime} 13^{\prime \prime} \mathrm{N}, 5^{\circ} 31^{\prime} 38^{\prime \prime} \mathrm{E}$ ) and Béchar (Coordinates: $31^{\circ} 37^{\prime} 00^{\prime \prime} \mathrm{N}$, $\left.2^{\circ} 13^{\prime} 00^{\prime \prime} \mathrm{W}\right)$, respectively. Plant identification and characterization was conducted using Quezel and Santa (1963) botanical criteria and authenticated by the Botanical professors at the National Superior School of Agronomy Algeria. The collected biomass was separated, cleaned and shade air-dried in a well-ventilated room, at room temperature. Dried plants were grounded to a fine powder $\left(\sim 20\right.$ mesh) and stored at $4{ }^{\circ} \mathrm{C}$ for further analyses.

\subsection{Chemical characterization of the plant material}

\subsubsection{Nutritional value}

Crude proteins, fat, carbohydrates and total ash content of the all samples were analyzed according to AOAC procedures (AOAC, 2016), and expressed in $\mathrm{g} / 100 \mathrm{~g}$ of dry weight. The crude protein content $(\mathrm{N} \times 6.25)$ was estimates through the macro-Kjeldahl method, whereas the crude fat content was determined after a Soxhlet extraction with petroleum ether. Incineration at $550 \pm 15^{\circ} \mathrm{C}$ was used to measure the total ash content. While total carbohydrates were calculated by difference and energetic value was calculated as following: Energy $(\mathrm{kcal})=4 \times(\mathrm{g}$ protein $+\mathrm{g}$ carbohydrates $)+9 \times(\mathrm{g}$ fat $)$.

\subsubsection{Elemental mineral composition}

For mineral elements determination, each sample $(0.5 \mathrm{~g})$ was weighed in a Teflon recipients and an acid digestion $\left(69 \% \mathrm{HNO}_{3}\right.$ and $30 \% \mathrm{H}_{2} \mathrm{O}_{2}$ ) at $110^{\circ} \mathrm{C}$ for $30 \mathrm{~min}$, in a High Performance Microwave Digestion system (ETHOS one-Milestone), was performed. The digested samples were filtered and poured into a $100 \mathrm{~mL}$ vial. The Teflon recipients were rinsed repeatedly by ultrapure water to make a total volume of $100 \mathrm{~mL}$, and then they were decanted into clean vials for the mineral determination. The absorbance was read in an atomic absorption spectrophotometer (Agilent Technologies, 240 FS AA) with nitrous oxide-acetylene flame, using different wavelength for each mineral element (Zn-213.9 nm, Ca-422.7 nm, Fe-248.3 nm, Mg-285.2 nm, Na$589 \mathrm{~nm}$, and K-766.5 nm). The absorbance responses were compared with $>99.9 \%$ purity analytical standard solutions for AAS, prepared with high purity, $\mathrm{Fe}\left(\mathrm{NO}_{3}\right)_{3}, \mathrm{Cu}\left(\mathrm{NO}_{3}\right)_{2}, \mathrm{Mn}\left(\mathrm{NO}_{3}\right)_{2}, \mathrm{Zn}\left(\mathrm{NO}_{3}\right)_{2}, \mathrm{NaNO}_{3}$, $\mathrm{KNO}_{3}, \mathrm{CaCO}_{3}$ and $\mathrm{Mg}\left(\mathrm{NO}_{3}\right)_{2}$, purchased from Sigma Aldrish TraceCERT $^{\circledast}$ AAS Standards.

\subsubsection{Free sugars}

The identification and quantitative of the free sugars present in the dry sample were determined by HPLC couple to a refraction index detector (Knauer, Smartline system 1000, Berlin, Germany), as previously described (Barros et al., 2013). Peaks identification was carried out by comparisons of their relative retention time (Rt) with authentic standards. While, quantification was performed using the internal standard (IS, melezitose, Sigma-Aldrich, St. Louis, MO, USA). Results were processed in a Clarity Software (Data Apex, Prague, Czech Republic) and expressed in $\mathrm{g}$ per $100 \mathrm{~g}$ of dry weight.

\subsubsection{Organic acids}

Organic acids content were determined using ultra-fast liquid chromatography (UFLC) (Shimadzu 20A UFLC series, Shimadzu Corporation, Kyoto, Japan) coupled to a diode array detector (DAD) operating under the conditions described by Barros et al. (2013). The detected compounds were identified and quantified (215 and $245 \mathrm{~nm}$, preference wavelengths) by comparing their peak area with calibration curves obtained from commercial standards. Results were processed using the LabSolutions Multi LC-PDA software and expressed in mg per $100 \mathrm{~g}$ of dry plant.

\subsubsection{Fatty acids}

The fatty acids content of the plant material was determined after trans-esterification as previously described by the authors Barros et al. (2013). The fatty acids profile was determined using a gas chromatographer (DANI model GC 1000, Contone, Switzerland) equipped with a split/splitless injector and a flame ionization detection (GC- FID, $260^{\circ} \mathrm{C}$ ). The identification was carried out by comparing the relative Rt of FAME (Fatty Acid Methyl Esters) peaks of the samples with commercial standards. Results were processed using Clarity Software (Data Apex, Prague, Czech Republic) and expressed in relative percentage.

\subsubsection{Tocopherols}

Tocopherols (four structural isoforms) were analyzed with using an 
HPLC (Knauer, Smartline system 1000) coupled with a fluorescence detector (excitation/emission detection at $290 / 330 \mathrm{~nm}$ ) as previously described by Barros et al. (2013). Identification was performed by chromatographic comparisons with authentic standards and quantification of the compounds was carried out using the IS (tocol) method though calibration curves obtained from commercial standards. Results were processed using Clarity Software (Data Apex, Prague, Czech Republic) and expressed in mg per $100 \mathrm{~g}$ of dry weight.

\subsection{Bioactive properties}

\subsubsection{Extracts preparation}

The hydroethanolic extracts were prepared by adding an ethanol/ water mixture $(8: 2, \mathrm{v} / \mathrm{v}, 30 \mathrm{~mL})$ to $1 \mathrm{~g}$ of dry powdered plant, the mixture was macerated twice for $1 \mathrm{~h}$ under stirring agitation. The extracts were filtered and evaporated under vacuum (rotary evaporator Büchi R-210, Flawil, Switzerland) at $35^{\circ} \mathrm{C}$ and the aqueous dark green residue was frozen $\left(-20^{\circ} \mathrm{C}\right)$, and then lyophilized $\left(-49^{\circ} \mathrm{C}\right.$ and 0.041 bar, FreeZone 4.5, Labconco, Kansas City, MO, USA) before subsequent analyzes.

The decoction is the usual form of administration of these plants as described by traditional healers. Therefore, decoctions were performed in a laboratory scale, in which each plant sample $(1 \mathrm{~g})$ was mixed with distilled water $(200 \mathrm{~mL})$ and then are left to boil, afterword's they are cooked for an additional $5 \mathrm{~min}$ in a closed recipient, filtered under reduced pressure, frozen $\left(-20^{\circ} \mathrm{C}\right)$, and lyophilized.

\subsubsection{Phenolic compounds analysis by HPLC-DAD-ESI/MSn}

The phenolic compounds were determined following a methodology previously described by the authors Bessada, Barreira, Barros, Ferreira, and Oliveira (2016). The extracts were prepared at a ratio of 10:1 (w/v) of dry extract/ultrapure water for the decoction extract and in ethanol/ water (80:20 v/v, HPLC-grade) for the hydroethanolic extract. Afterwards, the samples were filtrated (Whatman $0.45 \mu \mathrm{M}$ syringe filter), prior to the HPLC-DAD-ESI/MSn analysis (Dionex Ultimate 3000, Thermo Finnigan, San Jose, CA, USA). The compounds were detected using a diode array detector (DAD, recording at 280, 330 and $370 \mathrm{~nm}$ ), and a Linear Ion Trap LTQ XL mass spectrometer (ThermoFinnigan, San Jose, CA, USA), operating in negative mode. Identification was performed by comparing retention times (RT) and mass spectrum fragments with literature reported data or by comparison with commercially available standards (Extrasynthesis, Genay, France). Quantification was made on the basis of the UV-vis signal of each available phenolic standards, where calibration curves were obtained by injecting known concentrations $(2.5-100 \mu \mathrm{g} / \mathrm{mL})$. Results were processed using the Xcalibur ${ }^{\circledR}$ data system and expressed in mg per $g$ of extract.

\subsubsection{Cytotoxicity activity}

The cytotoxicity was conducted as described by Barros et al. (2013), using a concentration of $8 \mathrm{mg} / \mathrm{mL}$ of the aqueous decoction and hydroethanolic extract, both dissolved in ultrapure water. The sulforhodamine B colorimetric assay was applied in order to determine the inhibitory growth activity of four human tumor cell lines: NCI-H460 (non-small cell lung cancer), HeLa (cervical carcinoma), HepG2 (hepatocellular carcinoma), and MCF-7 (breast carcinoma).

The hepatotoxicity was determined using a primary culture of nontumor liver cells (PLP2), which were prepared from a freshly harvested porcine liver according to a procedure established by the authors Barros et al. (2013).

Ellipticine was used as positive control. Colorimetric readings were recorded using a Microplate Reader ELX800 (Bio-Tek Instruments, Inc., Winooski, VT, USA), and results were expressed as $\mathrm{GI}_{50}$ values, which represents the samples concentrations required to inhibit $50 \%$ of cell growth.

\subsubsection{Anti-inflammatory activity}

The concentration of nitrite NO produced by lipopolysaccharide (LPS)-stimulated murine macrophages RAW 264.7 cell lines in culture medium, treated with different concentrations of the plant extracts, was determined by a method previously described by Sobral et al. (2016). For this purpose, the crude aqueous extract (decoction) and the hydroethanolic extract, were dissolved at a concentration of $8 \mathrm{mg} / \mathrm{mL}$ in water and the production of nitric oxide (NO) was measured using the Griess reagent system kit and Dexamethasone was used as a positive control. Results were expressed as $\mathrm{EC}_{50}$ values corresponding to the sample concentration achieving $50 \%$ of the inhibition of NO-production.

\subsubsection{Antibacterial activity}

Crude extracts were screened for antibacterial activity against a panel of Gram-positive and Gram-negative Multidrug resistant (MDR) bacteria donated from the Local Health Unit of Bragança and Hospital Centre of Trás-os-Montes and Alto-Douro-Vila Real, Northeast of Portugal, therefore there was no direct contact with the patients. Four Gram-positive bacteria: Enterococcus faecalis, isolated from urine, Listeria monocytogenes, isolated from cerebrospinal fluid, methicillinsensitive Staphylococcus aureus (MSSA), isolated from wound exudate, and methicillin-resistant Staphylococcus aureus (MRSA), isolated from expectoration, and five Gram-negative bacteria: Escherichia coli, isolated from urine, Proteus mirabilis, isolated from wound exudate, Klebsiella pneumoniae, isolated from urine, Pseudomonas aeruginosa, isolated from expectoration and Morganella morganii, isolated from urine, were used to determine this bioactivity. The minimum inhibitory concentration (MIC) values were evaluated using a colorimetric assay of $p$-iodonitrotetrazolium chloride (INT) following a procedure ascribed by Pires et al. (2018). The MBC (minimal bactericidal concentrations) were determined by subculturing the culture from each negative well and from the positive control, and further incubated at $37^{\circ} \mathrm{C}$ for $24 \mathrm{~h}$.

Three negative controls were prepared, consisting of MuellerHinton broth (MHB), the extract, and a third with the medium and the antibiotic. A positive control was prepared with MHB and for each inoculum. Antibiotics, such as ampicillin and imipenem, have been used as positive controls for Gram-negative bacteria, while ampicillin and vancomycin were used for Gram-positive bacteria.

\subsection{Statistical analysis}

For all the extracts and tests, analyses were carried out in triplicate and the obtained values were expressed as the mean \pm standard deviation (SD). Statistics treatments was performed by SPSS v. 22.0 program (IBM Corp., Armonk, NY, USA) using one-way analysis of variance (ANOVA) followed by Tukey's HSD Test with $\alpha=0.05$. A students $t$-test was used to determine the significant difference among two different samples, with $\alpha=0.05$.

\section{Results and discussion}

\subsection{Chemical characterization}

The macronutrients composition and energetic value results obtained for the studied plants are presented in Table 1. Carbohydrates were found to be predominate compounds in both plant species, ranging from $65.0 \pm 1.0 \mathrm{~g} / 100 \mathrm{~g} \mathrm{dw}$ in A. leucotrichus to $56.6 \pm 0.5 \mathrm{~g} /$ $100 \mathrm{~g} \mathrm{dw}$ in $M$. oleifera, where reducing sugars constitute a small amount, representing 8.23 and $6.74 \%$ of the whole carbohydrates found in the studied species, respectively. Soluble sugars are usually represented by three naturally occurring molecules and widely distributed, such as glucose, fructose, and sucrose (Barros, Morales, Sanchez-Mata, Oliveira, \& Ferreira, 2015). Chromatographic analysis using HPLC-RI allowed their detection and quantification in the studied plant, with the highest total soluble sugars content in A. leucotrichus 
Table 1

Nutritional and energetic value, soluble sugars, and organic acids composition in A. leucotrichus aerial parts and M. oleifera leaves.

\begin{tabular}{|c|c|c|c|}
\hline & A. leucotrichus & M. oleifera & $\begin{array}{l}p \text {-Students } t \text { - } \\
\text { test }\end{array}$ \\
\hline Crude fat $(g / 100 g$ dw) & $11.1 \pm 0.3$ & $6.5 \pm 0.2$ & $<0.001$ \\
\hline Crude protein $(\mathrm{g} / 100 \mathrm{~g} \mathrm{dw})$ & $13.1 \pm 0.9$ & $22.8 \pm 0.3$ & $<0.001$ \\
\hline Total ash $(\mathrm{g} / 100 \mathrm{~g} \mathrm{dw})$ & $10.8 \pm 0.2$ & $14.1 \pm 0.5$ & 0.001 \\
\hline \multicolumn{4}{|l|}{ Macroelements } \\
\hline $\mathrm{Na}(\mathrm{mg} / 100 \mathrm{~g} \mathrm{dw})$ & $160 \pm 6$ & $319 \pm 6$ & $<0.001$ \\
\hline $\mathrm{Mg}(\mathrm{mg} / 100 \mathrm{~g} \mathrm{dw})$ & $236.6 \pm 0.4$ & $382 \pm 1$ & $<0.001$ \\
\hline $\mathrm{K}(\mathrm{mg} / 100 \mathrm{~g} \mathrm{dw})$ & $2283.1 \pm 0.4$ & $1626 \pm 1$ & $<0.001$ \\
\hline $\mathrm{Ca}(\mathrm{mg} / 100 \mathrm{~g} \mathrm{dw})$ & $1555 \pm 2$ & $2785 \pm 1$ & $<0.001$ \\
\hline \multicolumn{4}{|l|}{ Microelements } \\
\hline $\mathrm{Fe}(\mathrm{mg} / 100 \mathrm{~g} \mathrm{dw})$ & $22 \pm 2$ & $39 \pm 3$ & $<0.001$ \\
\hline $\mathrm{Zn}(\mathrm{mg} / 100 \mathrm{~g} \mathrm{dw})$ & $1.72 \pm 0.04$ & $3.37 \pm 0.09$ & $<0.001$ \\
\hline $\mathrm{Cu}(\mathrm{mg} / 100 \mathrm{~g} \mathrm{dw})$ & $0.39 \pm 0.03$ & $0.81 \pm 0.01$ & $<0.001$ \\
\hline $\mathrm{Mn}(\mathrm{mg} / 100 \mathrm{~g} \mathrm{dw})$ & $7.6 \pm 0.4$ & $5.21 \pm 0.03$ & $<0.001$ \\
\hline $\begin{array}{l}\text { Total carbohydrates }(\mathrm{g} / 100 \mathrm{~g} \\
\mathrm{dw})\end{array}$ & $65 \pm 1$ & $56.6 \pm 0.5$ & $<0.001$ \\
\hline Fructose $(\mathrm{g} / 100 \mathrm{~g} \mathrm{dw})$ & $1.0 \pm 0.1$ & $0.36 \pm 0.02$ & $<0.001$ \\
\hline Glucose $(\mathrm{g} / 100 \mathrm{~g} \mathrm{dw})$ & $2.6 \pm 0.1$ & $0.420 \pm 0.004$ & $<0.001$ \\
\hline Sucrose $(\mathrm{g} / 100 \mathrm{~g} \mathrm{dw})$ & $1.8 \pm 0.2$ & $3.04 \pm 0.07$ & $<0.001$ \\
\hline $\begin{array}{l}\text { Total soluble sugars }(\mathrm{g} / \\
100 \mathrm{~g} \mathrm{dw})\end{array}$ & $5.4 \pm 0.4$ & $3.82 \pm 0.09$ & $<0.001$ \\
\hline $\begin{array}{l}\text { Energetic value (Kcal/100 g } \\
\quad \mathrm{dw} \text { ) }\end{array}$ & $413 \pm 1$ & $376 \pm 1$ & $<0.001$ \\
\hline Oxalic acid (g/100 g dw) & $0.728 \pm 0.008$ & $1.35 \pm 0.03$ & $<0.001$ \\
\hline Malic acid $(\mathrm{g} / 100 \mathrm{~g} \mathrm{dw})$ & $2.5 \pm 0.1$ & $3.60 \pm 0.008$ & $<0.001$ \\
\hline Ascorbic acid (mg/100 g dw) & $5.6 \pm 0.1^{*}$ & $6.7 \pm 0.2^{*}$ & 0.711 \\
\hline $\begin{array}{l}\text { Total organic acids }(\mathrm{g} / 100 \mathrm{~g} \\
\quad \mathrm{dw})\end{array}$ & $3.3 \pm 0.1$ & $4.97 \pm 0.04$ & $<0.001$ \\
\hline
\end{tabular}

Values in mean values \pm standard deviation.

* Results expressed in $\mathrm{mg} / 100 \mathrm{~g}$ dw.

$(5.4 \pm 0.4 \mathrm{~g} / 100 \mathrm{~g} \mathrm{dw})$, being the main sugar, the reducing monosaccharide glucose $(2.6 \pm 0.1 \mathrm{~g} / 100 \mathrm{~g} \mathrm{dw})$. While $M$. oleifera leaves contained the lowest concentrations of soluble sugars. Similar values of carbohydrates (ranging from 54.6 to $57.6 \%$ ) were reported by Amabye (2016) in a sample of M. oleifera obtained commercially from Mekelle, Ethiopia. Nevertheless, Oduro, Ellis, and Owusu (2008) reported a lower amount of carbohydrates $(43.88 \mathrm{~g} / 100 \mathrm{~g})$ in the dry leaves of this species from Ghana. Samples of M. oleifera leaves from Ouagadougou (Yaméogo et al., 2011) also showed a lower level of carbohydrates (38.6 g/100 g of dry matter). Upadhyay et al. (2015) reported L-arabinose, D-galactose, D-glucuronic acid, L-rhamnose, D-mannose, and Dxylose to be predominant sugars in the purified whole-gum exudates of M. oleifera. The differences observed could be attributed to some exotic conditions, such as environmental and edaphoclimatic factors including temperature, topography and soil variations, but also to some biotic conditions (genetics, metabolism, between other factors) that may influence biochemical and physiological processes involved in the plant sugars' synthesis. To the author's best knowledge there is no report concerning carbohydrates and soluble sugars' content in A. leucotrichus.

Total ash content (Table 1) was also significant in both plant species, but $M$. oleifera $(14.1 \pm 0.5 \mathrm{~g} / 100 \mathrm{~g} \mathrm{dw})$ revealed the highest content. The obtained results for $M$. oleifera are corroborate with the reported data from literature, in which a commercial sample of $M$. oleifeira from Ethiopia (Amabye, 2016) presented a similar ash content (10.71 to $11.18 \mathrm{~g} / 100 \mathrm{~g}$ ), while Oduro et al. (2008) studied the leaves of $M$. oleifera collected from Ghana and presented a lower amount $(7.13 \mathrm{~g} / 100 \mathrm{~g})$. The amount of ash significantly influences the content of minerals, and indeed the minerals detected by AAS confirms this mineralogical richness. It was noticed a clear predominance of the macroelements and microelements in M. oleifera, in comparison to A. leucotrichus, with the exception of $\mathrm{Cu}$. Previous works concluded that leaves of the Moringa tree appeared to provide a broad range of important minerals essential for the human diet, especially $\mathrm{P}, \mathrm{K}, \mathrm{Ca}, \mathrm{Mg}$, $\mathrm{Mn}, \mathrm{Fe}, \mathrm{Al}, \mathrm{Cu}, \mathrm{Zn}$, and Na (Witt, 2013). Moyo et al. (2011) found $\mathrm{Ca}$
(3.65 g/100 g), P (0.3 g/100 g), Mg (0.5 g/100 g), K (1.5 g/100 g), Na (0.164 g/100 g), S (0.63 g/100 g), Zn (13.03 mg/kg), Cu ( $8.25 \mathrm{mg} / \mathrm{kg})$, $\mathrm{Mn}(86.8 \mathrm{mg} / \mathrm{kg}), \mathrm{Fe}(490 \mathrm{mg} / \mathrm{kg})$, and Se $(363 \mathrm{mg} / \mathrm{kg})$ in South African M. oleifera leaves, which were similar to the amounts present in this study. Also similar to the current findings, Amabye (2016) also revealed high values of macroelements in $M$. oleifera (from Ethiopia), Ca (2016.5-2620.5 mg/100 g), K (1817-1845 mg/100 g), and $\mathrm{Mg}$ (322.5-340.6 mg/100 g). Kane et al. (2017) studied M. oleifera dried leaves from the botanical garden of Dakar University (Senegal), and reported that $\mathrm{P}(1675.52 \mathrm{mg} / 100 \mathrm{~g}), \mathrm{Ca}(583.3 \mathrm{mg} / 100 \mathrm{~g})$, and $\mathrm{Mg}$ $(306.19 \mathrm{mg} / 100 \mathrm{~g})$ as the major mineral elements, which were also the predominant macroelements in the kernels and leaves of $M$. oleifera from India (Stadtlander \& Becker, 2017). The differences found regarding the mineral composition of the same species, may be attributed to the geographic diversity in the origin of these samples (Pires et al., 2018). Also, to the author's best knowledge there is no literature information regarding ash and mineral content in A. leucotrichus.

Concerning the protein fraction (Table 1 ), a significant high content was recorded in both plant species, thus $M$. oleifera revealed the highest levels $(22.8 \pm 0.3 \mathrm{~g} / 100 \mathrm{~g} \mathrm{dw})$. Previous research in this species also described high protein levels, considering this plant as a rich source of protein for dietary supplement (Oyeyinka \& Oyeyinka, 2016). Moreover, the same findings $(22.42 \mathrm{~g} / 100 \mathrm{~g}$ of dry weight) were also recorded by Sánchez-Machado, Núñez-gastélum, and Reyes-moreno (2009) in M. oleifera leaves from Mexico. These contents were also in accordance with those reported by Asante, Nasare, Tom-dery, and Ochire-boadu (2014), studing $M$. oleifera leaves from the semi-deciduous forest zone of Ghana. However, Guinea savanna M. oleifera leaves revealed slightly higher values (25.34 and $26.98 \mathrm{~g} / 100 \mathrm{~g} \mathrm{dw}$ ) (Asante et al., 2014). Nevertheless, Amabye (2016) presented a lower content ( 10.74 to $11.48 \mathrm{~g} / 100 \mathrm{~g}$ dry leaf powder) in the commercial sample of M. oleifera from Mekelle. Other studies have reported variable levels of protein contents in M. oleifera leaves ranging between 27.2 and $32.3 \mathrm{~g} /$ $100 \mathrm{~g}$ dw (Moyo et al., 2011; Oduro et al., 2008; Stadtlander \& Becker, 2017; Yaméogo et al., 2011). These findings highlights Moringa leaves as good sources of protein, with particular nutritional significance, as it may meet human's protein and energy requirements.

Different levels of crude fat were observed in the studied plants, with $A$. leucotrichus showing a higher content $(11.1 \pm 0.3 \mathrm{~g} / 100 \mathrm{~g} \mathrm{dw})$, comparatively to $M$. oleifera, presenting remarkably lower contents $(6.5 \pm 0.2 \mathrm{~g} / 100 \mathrm{~g} \mathrm{dw})$. These lower values of lipid contents were described by many previous scientific reports studying $M$. oleifera leaves. A content of $2.23 \mathrm{~g} / 100 \mathrm{~g}$ of fat was found in M. oleifera leaves from Ghana (Oduro et al., 2008), while the commercial Ethiopian $M$. oleifera ranged from 10.21 to $10.31 \mathrm{~g} / 100 \mathrm{~g} \mathrm{dw}$ (Amabye, 2016). The differences found in the fat content could be due to the analyzed plant part, which has specific influence on the fat distribution within the plant (generally concentrated in seeds), that could be affected by the plant genetics', the photoperiod, climatic conditions (temperature), and also to the extraction procedures applied.

A. leucotrichus revealed a higher energetic value than Moringa leaves, this being due to its higher carbohydrates and lipid content. Oduro et al. (2008) reported a similar energetic value in $M$. oleifera leaves from Ghana $(\sim 310 \mathrm{kcal} / 100 \mathrm{~g})$.

Three organic acids, such as oxalic, malic, and ascorbic acids, were identified and quantified in both studied species, being malic acid the predominant organic acid, followed by oxalic and ascorbic acids. $M$. oleifera showed the highest amounts of these compounds, with the exception of ascorbic acid, in which both species revealed a similar content. The noted variation between the species may be attributed to certain factors, including genetic and maturity levels of the species, which may affect the organic acids metabolism. However, according to Dias et al. (2016) several external processes, such as harvest and storage conditions, treatment, processing and preparation steps, may also contribute to the differences found in the organic acids composition. No data were found in literature regarding the organic acids profile for 
Table 2

Fatty acids (relative percent) and tocopherols composition in A. leucotrichus aerial parts and $M$. oleifera leaves.

\begin{tabular}{|c|c|c|c|}
\hline & A. leucotrichus & M. oleifera & $\begin{array}{l}p \text {-Students } t \text { - } \\
\text { test }\end{array}$ \\
\hline C8:0 & $0.166 \pm 0.001$ & $0.327 \pm 0.003$ & $<0.001$ \\
\hline C10:0 & $0.13 \pm 0.01$ & $0.29 \pm 0.01$ & $<0.001$ \\
\hline C11:0 & $1.67 \pm 0.07$ & $0.415 \pm 0.003$ & $<0.001$ \\
\hline C12:0 & $0.26 \pm 0.02$ & $0.46 \pm 0.02$ & $<0.001$ \\
\hline C13:0 & $2.038 \pm 0.002$ & $0.84 \pm 0.01$ & $<0.001$ \\
\hline $\mathrm{C} 14: 0$ & $0.87 \pm 0.05$ & $1.80 \pm 0.02$ & $<0.001$ \\
\hline C14:1 & $0.34 \pm 0.02$ & $0.57 \pm 0.01$ & $<0.001$ \\
\hline C15:0 & $0.37 \pm 0.02$ & $0.14 \pm 0.01$ & $<0.001$ \\
\hline C16:0 & $21.2 \pm 0.7$ & $17.160 \pm 0.001$ & $<0.001$ \\
\hline C16:1 & $1.06 \pm 0.01$ & $1.41 \pm 0.01$ & $<0.001$ \\
\hline $\mathrm{C} 17: 0$ & $0.72 \pm 0.01$ & $0.47 \pm 0.02$ & $<0.001$ \\
\hline C18:0 & $0.101 \pm 0.002$ & $2.67 \pm 0.05$ & $<0.001$ \\
\hline C18:1n9 & $53.8 \pm 0.4$ & $1.70 \pm 0.03$ & $<0.001$ \\
\hline $\mathrm{C} 18: 2 \mathrm{n} 6$ & $1.99 \pm 0.02$ & $13.10 \pm 0.06$ & $<0.001$ \\
\hline C18:3n3 & $10.6 \pm 0.4$ & $51.5 \pm 0.2$ & $<0.001$ \\
\hline C20:0 & $1.012 \pm 0.003$ & $0.92 \pm 0.01$ & $<0.001$ \\
\hline C20:1 & $1.179 \pm 0.002$ & $0.065 \pm 0.001$ & $<0.001$ \\
\hline C20:2 & $0.089 \pm 0.004$ & $0.073 \pm 0.001$ & $<0.001$ \\
\hline $\mathrm{C} 21: 0$ & $0.11 \pm 0.01$ & $0.085 \pm 0.001$ & $<0.001$ \\
\hline C22:0 & $1.23 \pm 0.01$ & $1.87 \pm 0.03$ & $<0.001$ \\
\hline C20:5n 3 & $0.357 \pm 0.004$ & $0.297 \pm 0.001$ & $<0.001$ \\
\hline $\mathrm{C} 24: 0$ & $0.741 \pm 0.003$ & $3.87 \pm 0.04$ & $<0.001$ \\
\hline SFA & $30.6 \pm 0.8$ & $31.3 \pm 0.1$ & 0.102 \\
\hline MUFA & $56.4 \pm 0.4$ & $3.75 \pm 0.02$ & $<0.001$ \\
\hline PUFA & $13.0 \pm 0.4$ & $64.9 \pm 0.1$ & $<0.001$ \\
\hline PUFA/SFA & $0.43 \pm 0.02$ & $2.07 \pm 0.01$ & $<0.001$ \\
\hline$\alpha$-Tocopherol & $0.69 \pm 0.04$ & $4.0 \pm 0.1$ & $<0.001$ \\
\hline$\beta$-Tocopherol & nd & $0.029 \pm 0.002$ & - \\
\hline$\gamma$-Tocopherol & nd & $0.41 \pm 0.02$ & - \\
\hline$\delta$-Tocopherol & nd & $0.068 \pm 0.002$ & - \\
\hline $\begin{array}{l}\text { Total tocopherol (mg/ } \\
\quad 100 \mathrm{~g} \mathrm{dw})\end{array}$ & $0.69 \pm 0.04$ & $4.5 \pm 0.1$ & $<0.001$ \\
\hline
\end{tabular}

Values expressed in mean values \pm standard deviation. nd - not detected; dw dry weight; Caprylic acid (C8:0); Capric acid (C10:0); Undecanoic acid (C11:0); Lauric acid (C12:0); Myristic acid (C14:0); Myristoleic acid (C14:1); Penta-decanoic acid (C15:0); Palmitic acid (C16:0); Heptadecanoic acid (C17:0); Stearic acid (C18:0); Oleic acid (C18:1n9c); Linoleic acid (C18:2n6c); a-Linolenic acid (C18:3n3); Arachidic acid (C20:0); Eicosanoic acid (C20:1); cis-11,14Eicosadienoic acid (C20:2c); cis-11,14,17-Eicosatrienoic acid; Behenic acid (C22:0); Lignoceric acid (C24:0). SFA - saturated fatty acids; MUFA - monounsaturated fatty acids; PUFA - polyunsaturated fatty acids.

\section{both species.}

The GC-FID analysis of fatty acids revealed the presence of twentytwo molecules in both plants species, thus revealing significant different contents (Table 2). However, linoleic acid (C18:2n6), oleic acid (C18:1n9), $\alpha$-linolenic acid (C18:3n3), and palmitic acid (C16:0) were the predominant fatty acids in both species. While PUFA (polyunsaturated fatty acids) predominated in $M$. oleifera leaves $(64.9 \pm 0.1 \%)$, due to the contribution of $\alpha$-linolenic acid (ALA, $51.5 \pm 0.2 \%$ ) and linoleic acid (LA, $13.10 \% \pm 0.06 \%$ ); MUFA (monounsaturated fatty acids) were the main group of compounds present in A. leucotrichus ( $56.4 \pm 0.4 \%$ ), with the highest contribution of oleic acid $(53.8 \pm 0.4 \%)$. This fact lead to low ration of PUFA/SFA in A. leucotrichus, thus $M$. oleifera presented a very high ratio of PUFA/ SFA, which is a very interesting criteria in the quality of crops and their biological functions (Dias et al., 2016).

Sánchez-Machado et al. (2009) also reported high percentages of $\alpha$ linolenic acid (56.87\%) in M. oleifera leaves from Sonora Mexico. Moyo et al. (2011) identified seventeen fatty acids in M. oleifera leaves from South-Africa, with $\alpha$-linolenic acid (44.57\%) as the most abundant fatty acid. The obtained amounts of ALA and LA in M. oleifera were higher than the published amount of Stadtlander and Becker (2017), who analyzed the lipid fraction of $M$. oleifera kernels from Nicaragua, India, and Ethiopia.
Moringa contains a higher percentage of PUFA, which is desirable for its inclusion in a healthy diet, as it may prevent the occurrence of certain diseases (Sánchez-Machado et al., 2009). Recently, essential fatty acids, such as ALA and LA, have been considered as a functional food and/or nutraceutical, which promote the endogenous biosynthesis of long chain n-3 PUFA, being important for the eicosanoids biosynthesis, which are viewed as important bio-regulators of many cellular processes (Arbex et al., 2015).

The tocopherols content in both studied species is shown in Table 2. M. oleifera revealed the presence of all four isomers, while A. leucotrichus only presented $\alpha$-tocopherol. This vitamer was the most abundant in $M$. oleifera, followed by $\gamma$-tocopherol, $\beta$-tocopherol, and $\delta$-tocopherol. Sánchez-Machado et al. (2006) found $\alpha$-tocopherol as the main isomer in $M$. oleifera leaves $(744.5 \mu \mathrm{g} / \mathrm{g})$ from Sonora, Mexico. The Algerian $M$. oleifera oil sample from kernels showed a significant higher value of total tocopherol $(287-327 \mathrm{mg} / \mathrm{kg}$ ), as well as the individual amounts of $\alpha$-tocopherol (195.8-263.2 mg/kg), $\beta$-tocopherol (4.7-10.5 mg/kg), $\gamma$-tocopherol $(51.2-77.8 \mathrm{mg} / \mathrm{kg}$ ), and $\delta$ - tocopherol (6.1-8.6 mg/kg) (Boukandoul et al., 2017). This higher content could be due to the fact that the previous authors use different plant parts, which certainly contain a higher content of this lipophilic vitamin.

Globally, the differences found between the obtained values and those reported in literature may be explained by several factors responsible for these variations, such as the impact of soil and climatic conditions, the maturity of analyzed samples, or changes in the extraction method applied.

\subsection{Phenolic profiling by HPLC-DAD-ESI/MS}

The chromatographic characteristics of the identified phenolic compounds are presented in Tables 3 and 4, for A. leucotrichus and $M$. oleifera, respectively. A. leucotrichus revealed the presence of 7 phenolic compounds, 2 phenolic acid derivatives and 5 flavones (apigenin and luteolin derivatives), while $M$. oleifera presented 12 compounds, of which 3 were phenolic acid derivatives and 9 were flavonoids, mainly flavonols (quercetin, kaempferol and isorhamnetin glycoside derivatives) and flavones (apigenin derivatives).

Regarding, A. leucotrichus extracts (Table 3 ), peak $3^{\mathrm{Al}}$ revealed a pseudomolecular ion at $m / z 601$ and based on its MS/MS fragmentation pattern, it was identified as di-O-caffeoyl-malonylquinic acid, as previously identified in a plant species of the same family Centella asiatica (Maulidiani, Abas, Khatib, Shaari, \& Lajis, 2014). Similarly, peak $6^{\mathrm{Al}}$ $\left([\mathrm{M}-\mathrm{H}]^{-} m / z 687\right)$ revealed $86 \mathrm{u}$ (malonyl moiety) higher then peak $3^{\mathrm{Al}}$, being tentatively identified as di-O-caffeoyl-dimalonylquinic acid. The remaining compounds (peaks $1^{\mathrm{Al}}, 2^{\mathrm{Al}}, 4^{\mathrm{Al}}, 5^{\mathrm{Al}}$, and $7^{\mathrm{Al}}$ ) corresponded to flavone derivatives, in which peak $2^{\mathrm{Al}}$ (luteolin-7-O-glucoside) was positively identified in comparison with the commercial standard. Two apigenin derivatives were found in the extracts, peak $1^{\mathrm{Al}}$ ([M-H] $]^{-} m / z 593$ ) corresponded to a $C$-glycoside due to its characteristic losses of 90 and $30 \mathrm{u}$ moieties, being tentatively identified as apigenin-6,8-C-diglucoside, as previously described by Makita, Chimuka, Steenkamp, Cukrowska, and Madala (2016) and Karthivashan, Arulselvan, Alimon, Ismail, and Fakurazi (2015). Peak $7^{\mathrm{Al}}\left([\mathrm{M}-\mathrm{H}]^{-} m / z\right.$ 473) presented one $\mathrm{MS}^{2}$ fragment at 269 , corresponding to apigenin aglycone with the loss of $42 \mathrm{u}+162 \mathrm{u}$ (acetyl and hexosyl moieties), therefore being tentatively identified as apigenin- $O$ (acetyl-hexoside). Finally, the two remaining compounds presented a pseudomolecular ion at $\mathrm{m} / \mathrm{z} 533$ with two $\mathrm{MS}^{2}$ fragments at 489 and 285 , revealing the loss of a malonyl $(-86 \mathrm{u})$ and hexosyl $(-162 \mathrm{u})$ moiety, and therefore tentatively identified as luteolin-O-(malonylhexoside) isomer 1 and 2.

Luteolin derivatives, such as luteolin-7-O-glucoside and luteolin-O(malonyl-hexoside) were the major compounds present (Table 3), and the hydroethanolic extract revealed the highest content. To the author's best knowledge there is no reports regarding the individual identification of phenolic compounds in this species. Nevertheless, El Haci et al. 
(2018) studied the total phenolic and flavonoid contents of A. leucotrichus fruits from Algeria; Sebaa, Marouf, Kambouche, and Derdour (2018) also studied the fruits of this species, but performed a preliminary screening of group of compounds through a silica TLC assay, revealing the presence of anthracenes, tannins, alkaloids, phenolic acids, cardiotonic glucoses, saponins, flavonoids, and coumarins. Although, in the present study only phenolic acids and flavonoids were detected, these differences could be due to the different plant parts studied, as also to the extraction solvents applied. Finally, Halla et al. (2018) described the presence of the following group of compounds, flavonoids, tannins, coumarins, alkaloids, and terpenoids, in A. leucotrichus hydromethanolic extracts from Algeria, but the authors did not mentioned the part studied. These authors determined phenolic compounds through colorimetric reactions. Nevertheless, none of the mentioned authors presented a full characterization using chromatographic methodologies.

Meanwhile, $M$. oleifera is a well-studied plant species, in which all the detected phenolic compounds (Table 4) have been previously identified (Amaglo, Bennett, Lo Curto, Rosa, Lo Turco, Giuffrida, Lo Curto, Crea, \& Timpo, 2010; Bennett et al., 2003; Coppin et al., 2013; Karthivashan et al., 2015; Karthivashan, Fard, Arulselvan, Abas, \& Fakurazi, 2013; Makita et al., 2016, 2017; Nouman et al., 2016). Thus, to the author's best knowledge, $M$. oleifera with Algerian origin has not been previously reported in literature. Moreover, none of the mentioned authors revealed the exact phenolic profile, but some of the herein identified compounds have been previously described. Therefore, considering the pseudomolecular ion, fragmentation pattern and UV-vis spectra found, the studied herein compounds were tentatively identified. Peak $1^{\mathrm{Mo}}$ and $3^{\mathrm{Mo}}\left([\mathrm{M}-\mathrm{H}]^{-} \mathrm{m} / \mathrm{z} 353\right)$ and peak $2^{\mathrm{Mo}}\left([\mathrm{M}-\mathrm{H}]^{-}\right.$ $\mathrm{m} / \mathrm{z}$ 337) were assigned as 3-O- and 4-O-caffeoylquinic acid, and 3-pcoumaroylquinic acid, respectively. These assumptions were taken into account, due to the hierarchical fragmentation pattern described by Clifford, Johnston, Knight, \& Kuhnert, 2003, but also by using literature data described by other authors. Makita et al. (2017) studied M. ovalifolia leaves from Namibia using an UPLC-ISCID-MS/MS, and profiled various isomers of chlorogenic acids in the aqueous methanol (80\%) extract, which allowed the positive identification of compounds $1^{\mathrm{Mo}}$, $2^{\mathrm{Mo}}$ and $3^{\mathrm{Mo}}$. Nouman et al. (2016) revealed the presence of compounds $1^{\mathrm{Mo}}$ and $2^{\mathrm{Mo}}$ in the hydromethanolic extracts $(70 \%)$ of $M$. oleifera seeds from cultivars collected from China and Pakistan. While, Bennett et al. (2003) only revealed the presence of compound $1^{\mathrm{Mo}}$ in the methanolic extract $(70 \% \mathrm{v} / \mathrm{v})$ of $M$. oleifera young leaves from many locations in Nicaragua and Malawi. This compound (peak $1^{\mathrm{Mo}}$ ) was also present in the methanolic extract (70\%) of the Ghanaian M. oleifera stems, leaves, and flowers (Amaglo et al., 2010).

The remaining compounds refer to flavonoid derivatives, such as quercetin ( $\lambda_{\max }$ around $350 \mathrm{~nm}$ and an $\mathrm{MS}^{2}$ fragment at $m / z 301$ ), kaempferol ( $\lambda_{\max }$ around $348 \mathrm{~nm}, \mathrm{MS}^{2}$ fragment at $m / z 285$ ), isorhamnetin ( $\lambda_{\max }$ at $354 \mathrm{~nm}, \mathrm{MS}^{2}$ fragment at $m / z 315$ ), and a flavone, apigenin ( $\lambda_{\max }$ around $336 \mathrm{~nm}, \mathrm{MS}^{2}$ fragment at $\left.m / z 269\right)$. Compounds $5^{\text {Mo }}$ (quercetin-3-O-rutinoside), $6^{\text {Mo }}$ (apigenin-6- $C$-hexoside), $7^{\text {Mo }}$ (quercetin-3-O-glucoside), and $10^{\mathrm{Mo}}$ (quercetin-3-O-rhamnoside), were positively identified in comparison with the commercial standards. While compounds $8^{\mathrm{Mo}}$ and $9^{\mathrm{Mo}}\left([\mathrm{M}-\mathrm{H}]^{-} \mathrm{m} / z\right.$ 549), $11^{\mathrm{Mo}}\left([\mathrm{M}-\mathrm{H}]^{-} \mathrm{m} / z\right.$ 533), and $12^{\mathrm{Mo}}\left([\mathrm{M}-\mathrm{H}]^{-} m / z 563\right)$ were identified as malonyl-glucoside derivatives of quercetin, kaempferol and isorhamnetin, respectively. Finally, compound $4^{\mathrm{Mo}}\left([\mathrm{M}-\mathrm{H}]^{-} m / z 593\right)$ was identified as apigenin6,8-C-diglucoside, taking into the findings described above for $A$. leucotrichus extracts.

Quercetin-3-O-(6"-malonyl-glucoside) was the most abundant compound present in $M$. oleifera, followed by the phenolic acid, 3-Ocaffeoylquinic acid.

Makita et al. (2016) studied an 80\% aqueous methanol extract of $M$. oleifera from three different locations in Namibia. These authors profiled the phenolic composition using an UHPLC-ESI-qTOF-MS system, revealing the presence of 17 compounds of which five were found in the 


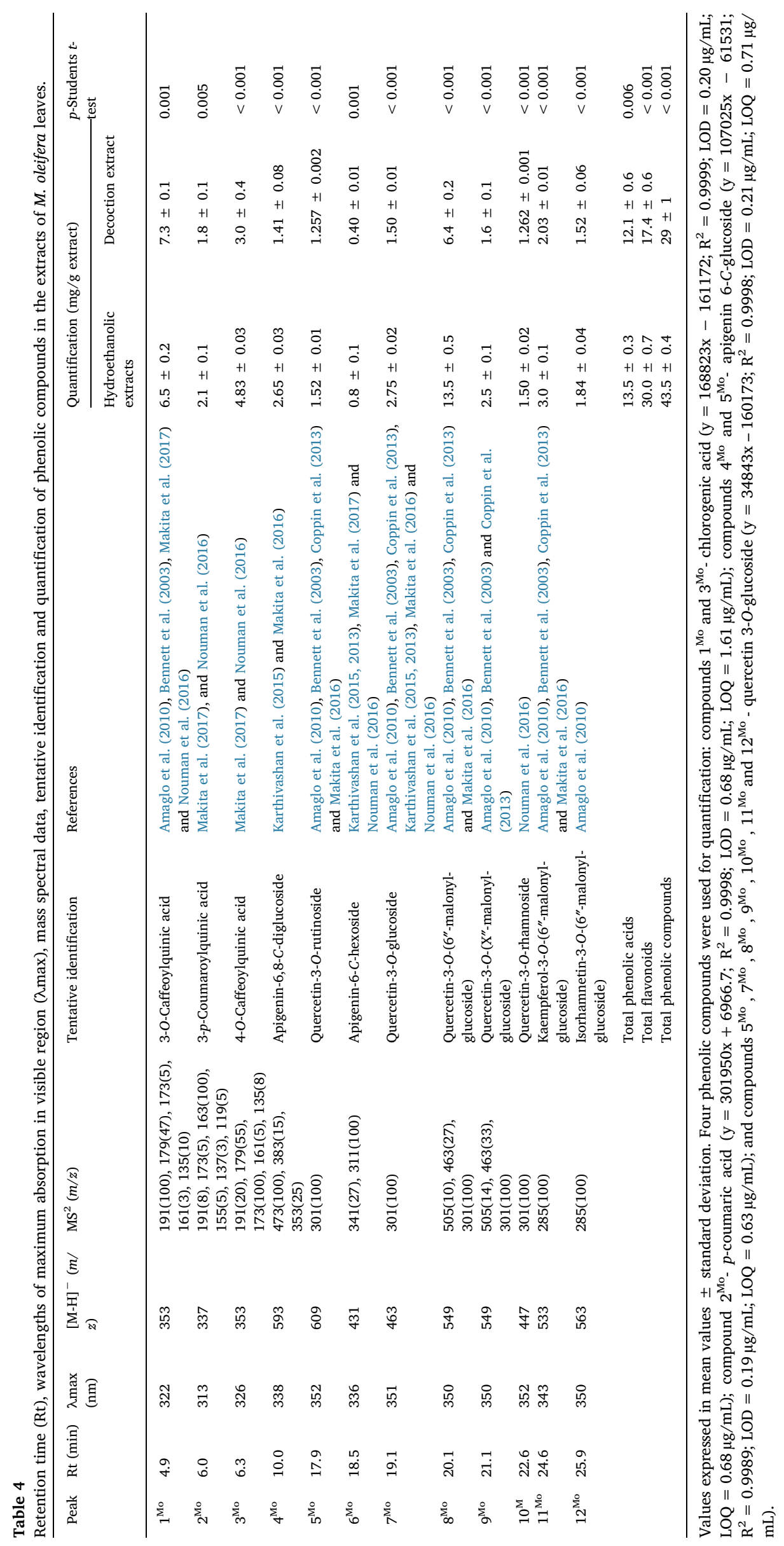


Table 5

Cytotoxic and anti-inflammatory properties of A. leucotrichus and M. oleifera decoctions and hydroethanolic extracts.

\begin{tabular}{|c|c|c|c|c|c|c|}
\hline & & A. leucotrichus & & M. oleifera & & \\
\hline Cytotoxicity & Cell lines & Hydroethanolic & Decoction & Hydroethanolic & Decoction & Ellipticine \\
\hline \multirow[t]{5}{*}{ Growth inhibition values $\left(\mathrm{GI}_{50}, \mu \mathrm{g} / \mathrm{mL}\right)$} & NCI-H460 & $179 \pm 3 c$ & $>400$ & $226.5 \pm 0.8 b$ & $235.9 \pm 0.4 a$ & $1.03 \pm 0.09$ \\
\hline & HeLa & $79.8 \pm 0.2^{*}$ & $>400$ & $>400$ & $142.9 \pm 0.9^{*}$ & $1.91 \pm 0.06$ \\
\hline & HepG2 & $126.8 \pm 0.8 b$ & $>400$ & $99.2 \pm 0.4 \mathrm{c}$ & $199.2 \pm 0.7 \mathrm{a}$ & $1.1 \pm 0.2$ \\
\hline & MCF-7 & $54 \pm 1 c$ & $>400$ & $192 \pm 3 a$ & $186.0 \pm 0.8 b$ & $0.91 \pm 0.04$ \\
\hline & PLP2 & $239.5 \pm 0.3 c$ & $>400$ & $327 \pm 1 \mathrm{a}$ & $313 \pm 4 b$ & $3.2 \pm 0.7$ \\
\hline \multicolumn{7}{|l|}{ Anti-inflammatory } \\
\hline Nitric oxide NO-production $\left(\mathrm{EC}_{50}, \mu \mathrm{g} / \mathrm{mL}\right)$ & RAW264.7 & $251 \pm 14 c$ & $>400$ & $294 \pm 10 b$ & $321 \pm 8 a$ & $16 \pm 1$ \\
\hline
\end{tabular}

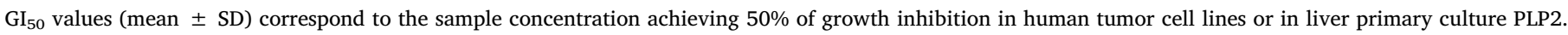

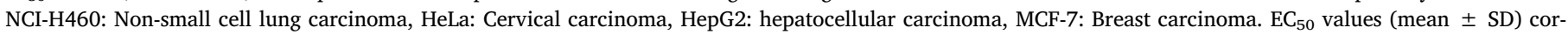

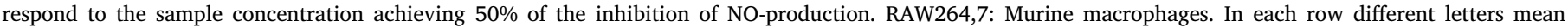

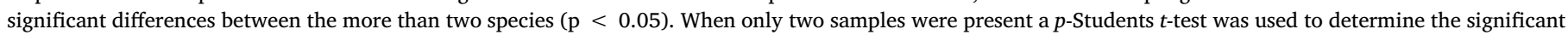
difference with $\alpha=0.05$.

* Means a significant difference between the samples $(\mathrm{p}<0.05)$.

present study (compounds $4^{\mathrm{Mo}}, 5^{\mathrm{Mo}}, 7^{\mathrm{Mo}}, 8^{\mathrm{Mo}}$, and $11^{\mathrm{Mo}}$ ). While, Nouman et al. (2016) profiled three of the identified compounds $\left(6^{\mathrm{Mo}}\right.$, $7^{\mathrm{Mo}}$ and $10^{\mathrm{Mo}}$ ) in the hydromethanolic extract (70\%) of M. oleifera seeds obtained from different cultivars collected from China and Pakistan. Bennett et al. (2003) studied M. oleifera ethanolic extract (70\%) from Nicaragua, Malawi, Tanzania and Senegal using an LC-UV-Vis-ESI-MS system. These authors presented five compounds $\left(4^{\mathrm{Mo}}, 5^{\mathrm{Mo}}, 7^{\mathrm{Mo}}, 8^{\mathrm{Mo}}\right.$ and $9^{\mathrm{Mo}}$ ) in common with the herein studied extracts. Additionally, Karthivashan et al. (2013) revealed the presence of two of the identified compounds ( $6^{\text {Mo }}$ and $7^{\text {Mo }}$ ) in the hydroethanolic extracts of $M$. oleifera leaves from Malaysia, while compounds $4^{\mathrm{Mo}}$ and $6^{\mathrm{Mo}}$ were described in another work, using the aqueous extracts of the same species from Malaysia (Karthivashan et al., 2015). Moreover, Amaglo et al. (2010) and Coppin et al. (2013) identified compounds $5^{\mathrm{Mo}}, 7^{\mathrm{Mo}}, 8^{\mathrm{Mo}}, 9^{\mathrm{Mo}}$ and $11^{\text {Mo }}$ in $M$. oleifera leaves from Ghana and M. oleifera leaves collected from African sub-Sahara, respectively. Nevertheless, Amaglo et al. (2010) also detected compounds $4^{\mathrm{Mo}}$ and $12^{\mathrm{Mo}}$, respectively.

According to the phenolic compounds' quantification results (Tables 3 and 4), both plant species revealed higher values for the hydroethanolic extract in comparison to the decoction extract. A. leucotrichus revealed a high concentration in flavonoids $(24.2 \pm 0.4 \mathrm{mg} / \mathrm{g}$ extract), due to the presence of luteolin derivatives, such as luteolin-7-O-glucoside $(11.7 \pm 0.5 \mathrm{mg} / \mathrm{g}$ extract) and luteolin- $O$-(malonyl-hexoside) isomer $2(8.87 \pm 0.03 \mathrm{mg} / \mathrm{g}$ extract). Moreover, M. oleifera hydroethanolic extracts presented a higher amount of total phenolic compounds ( $43.5 \pm 0.4 \mathrm{mg} / \mathrm{g}$ extract), mostly due to the presence of total flavonoids ( $30.0 \pm 0.7 \mathrm{mg} / \mathrm{g}$ extract), and especially to the presence of flavonol glycosides, such as quercetin-3-O-(6"-malonyl-glucoside) (13.5 $\pm 0.5 \mathrm{mg} / \mathrm{g}$ extract), kaempferol-3-O-(6"-malonyl-glucoside) $(3.0 \pm 0.1 \mathrm{mg} / \mathrm{g} \quad$ extract $)$ and quercetin-3-O-glucoside $(2.75 \pm 0.02 \mathrm{mg} / \mathrm{g}$ extract $)$.

The same quantitative relation was previously reported for the hydroethanolic extract (70\%) of $M$. oleifera young leaves from Managua (Nicaragua) recording, 10.8, 2.6, and $4.1 \mathrm{mg} / \mathrm{g} \mathrm{dw}$ of the same compounds, respectively (Bennett et al., 2003). Moreover, these authors also reported that the $M$. oleifera young leaves extract (ethanolic 70\%) from Dakar (Senegal) and Zion Church (Malawi), also contained high amounts of quercetin-3-O-glucoside $(6.3 \mathrm{mg} / \mathrm{g}$ and $2.6 \mathrm{mg} / \mathrm{g} \mathrm{dw}$ respectively) and quercetin-3-O-(6"-malonyl-glucoside) $(3.5 \mathrm{mg} / \mathrm{g}$ and $3.9 \mathrm{mg} / \mathrm{g} \mathrm{dw}$ respectively). Amaglo et al. (2010) studied the ethanolic extract (70\%) of $M$. oleifera leaves and although reporting the presence of quercetin-3-O-(6"-malonyl-glucoside) $(1.5 \mathrm{mg} / \mathrm{g} \mathrm{fw})$ and quercetin-3$O$-glucoside $(0.65 \mathrm{mg} / \mathrm{g} \mathrm{fw})$, these were not the main compounds present. Out of the three main flavonoids present in our sample, only quercetin-3-O-glucoside was present in several cultivars of $M$. oleifera leaves from Pakistan, thus the quantities were not comparable, and apigenin-8-C-glucoside was reported as the main flavonoid (Nouman

\section{et al., 2016).}

An appreciable amount of total phenolic acids was also detected in the current study, being 3-O-caffeoylquinic acid (3-CQA), followed by 4-O-caffeoylquinic acid (4-CQA), and 3-p-coumaroylquinic acid (3CoQA) the most abundant compounds, respectively. 3-CQA was also found as the main phenolic acid in M. oleifera old and young leaves (6.2 and $8.9 \mathrm{mg} / \mathrm{g} \mathrm{dw}$, respectively) as reported by Bennett et al. (2003), which also showed similar values for this compound in other $M$. oleifera from different regions. Amaglo et al. (2010) also revelaed the presence of 3-CQA $(0.8 \mathrm{mg} / \mathrm{g} \mathrm{fw})$ and 4-CQA $(1.26 \mathrm{mg} / \mathrm{g} \mathrm{fw})$ in M. oleifera flowering season leaves. While, Nouman et al. (2016) also identified 3CQA as the main phenolic acid and smaller amounts of 3-CoQA in different cultivars of $M$. oleifera leaves from Pakistan.

The differences found in the phenolic composition profile and quantification could be due to the geographical origin of the plant and the different parts of the sample used, as also to the different extraction procedures. The applied methodologies for the individual phenolic compounds quantification could also lead to possible differences found in the amounts present, because the methodology could differ in their sensitivity and selectivity, and the standard compound used to quantify each one of the phenolic compounds present.

\subsection{Bioactive properties evaluation}

Herbal-induced cytostatic and cytotoxic effects can be therapeutically effective when directed to attack tumorigenesis proliferations (Kmail, Lyoussi, Zaid, \& Saad, 2015). A. leucotrichus and M. oleifera extracts were screened for their cytotoxic activities using four different cancer cell lines (Table 5). This assay reports the toxicity effects of the plant extracts against cell proliferation and metabolism (Son \& Anh, 2013). The $\mathrm{GI}_{50}$ values for the hydroethanolic extract were in general lower (higher activity) than the ones exhibited by decoction extracts (Table 5), showing a significant dose dependent cytotoxic effect. The cell lines MCF-7, HeLa, and NCI-H460 were the most susceptible for the hydroethanolic extract of A. leucotrichus, while HepG2 was more susceptible to $M$. oleifera hydroethanolic extract. A. leucotrichus decoction did not show any cytotoxic effects, while $M$. oleifera decoction extract presented moderated anti-proliferative activity. Nevertheless, regarding the cytotoxic effects in non-tumor cells, all the extracts, with the exception of A. leucotrichus decoction, presented certain inhibition effect, thus the $\mathrm{GI}_{50}$ value were higher than the ones needed to inhibit the human tumor cell lines.

Therefore, these results indicate that both plant extracts (except $A$. leucotrichus decoction) induced cytotoxic effects in all human tumor cell lines, and could be related to the diverse phenolic constituents of each plant extract. The mechanism of action of phenolic compounds has been related to the cell cycle block or delay in the cell proliferation, 
Table 6

Antibacterial activity (MIC and $\mathrm{MBC}, \mathrm{mg} / \mathrm{mL}$ ) of $M$. oleifera and $A$. leucotrichus decoctions and hydroethanolic extracts.

\begin{tabular}{|c|c|c|c|c|c|c|c|c|c|c|c|c|c|c|}
\hline \multirow[b]{3}{*}{ Antibacterial activity } & \multicolumn{4}{|c|}{ A. leucotrichus } & \multicolumn{4}{|c|}{ M. oleifera } & \multicolumn{6}{|c|}{ Antibiotics } \\
\hline & \multicolumn{2}{|c|}{ Hydroethanolic } & \multicolumn{2}{|c|}{ Decoction } & \multicolumn{2}{|c|}{ Hydroethanolic } & \multicolumn{2}{|c|}{ Decoction } & \multicolumn{2}{|c|}{ Ampicillin } & \multicolumn{2}{|l|}{ Imipenem } & \multicolumn{2}{|c|}{ Vancomycin } \\
\hline & MIC & MBC & MIC & MBC & MIC & MBC & MIC & $\mathrm{MBC}$ & MIC & $\mathrm{MBC}$ & MIC & MBC & MIC & MBC \\
\hline \multicolumn{15}{|l|}{ Gram-negative bacteria } \\
\hline Escherichia coli & 5 & $>20$ & 5 & $>20$ & 10 & $>20$ & 20 & $>20$ & $<0.15$ & $<0.15$ & $<0.0078$ & $<0.0078$ & nt & nt \\
\hline Klebsiella pneumoniae & 10 & $>20$ & 20 & $>20$ & 20 & $>20$ & 20 & $>20$ & 10 & 20 & $<0.0078$ & $<0.0078$ & nt & nt \\
\hline Morganella morganii & 5 & $>20$ & 20 & $>20$ & 5 & $>20$ & 10 & $>20$ & 20 & $>20$ & $<0.0078$ & $<0.0078$ & nt & nt \\
\hline Proteus mirabilis & 20 & $>20$ & $>20$ & $>20$ & $>20$ & $>20$ & $>20$ & $>20$ & $<0.15$ & $<0.15$ & $<0.0078$ & $<0.0078$ & nt & nt \\
\hline Pseudomonas aeruginosa & 2.5 & $>20$ & 20 & $>20$ & $>20$ & $>20$ & $>20$ & $>20$ & $>20$ & $>20$ & 0.5 & 1 & nt & nt \\
\hline \multicolumn{15}{|l|}{ Gram-positive bacteria } \\
\hline Enterococcus faecalis & $>20$ & $>20$ & $>20$ & $>20$ & 10 & $>20$ & 10 & $>20$ & $<0.15$ & $<0.15$ & nt & nt & $<0.0078$ & $<0.0078$ \\
\hline Listeria monocytogenes & 5 & $>20$ & 20 & $>20$ & 2.5 & $>20$ & 2.5 & $>20$ & $<0.15$ & $<0.15$ & nt & nt & nt & nt \\
\hline$M R S A$ & 5 & $>20$ & 5 & $>20$ & 10 & $>20$ & 20 & $>20$ & $<0.15$ & $<0.15$ & nt & nt & $<0.0078$ & $<0.0078$ \\
\hline$M S S A$ & 1.25 & $>20$ & 5 & $>20$ & 0.625 & $>20$ & 5 & $>20$ & $<0.15$ & $<0.15$ & nt & nt & 0.25 & 0.5 \\
\hline
\end{tabular}

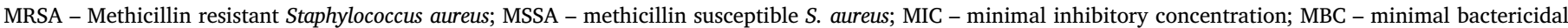
concentration, nt - not tested.

cytotoxicity based on DNA damage leading to an apoptosis, inhibition of angiogenesis, and interactions with topoisomerase (Carocho \& Ferreira, 2013). Edwinanto et al. (2018) indicated that the flavonoids (quercetin, kaempferol and myricetin) found in Moringa leaves can induce apoptosis through intrinsic pathways by inhibition of mitogenactivated protein kinase (MAPK), extracellular-signal-regulated kinase $1 / 2$ (ERK $1 / 2$ ), c-Jun N-terminal protein kinase 1 (JNK), and protein kinase C (PKC). Other authors (Tiloke et al., 2013) found Moringa leaves to be a potential source of antitumor agents, especially due to the presence of niaziminin, a thiocarbamate, that exhibits inhibition of tumor-promoter induced Epstein-Barr virus activation. In a study using Swiss mice, $M$. oleifera leaf paste increased glutathione-S-transferase (GST), as well as the crude ethanolic extract of seeds, which exhibited anti-tumor potential against Epstein-Barr virus-early antigen (EBV-EA) (Goyal, Agrawal, Goyal, \& Mehta, 2007). Additionally, aqueous extract of $M$. oleifera induced apoptosis in KB carcinoma cells (Sreelatha \& Padma, 2011), and can act as an anticancer agent in lung cancer by inducing cellular apoptosis and subsequent cell death (Tiloke et al., 2013). The phytochemical constituents of $M$. oleifera extracts, such as glucosinolates, isothiocyanates, niazimicin, niaziminin, and quercetin, were shown to possess anti-proliferative effects in a diverse of cell lines (Purwal, Pathak, \& Jain, 2010; Tiloke et al., 2013). In addition, niazimicin and 4-(4'-O-acetyl- $\alpha$-L-rhamnopyranosyloxy) benzyl isothiocyanate were identified as natural anticancer agents and were positively compared with the recommended chemotherapeutic drug. These phytochemicals enhanced the activity of cellular prostatic acid phosphatase and possessed less toxicity, thus showing potential as a potent and safe natural agent in prostate cancer therapy and drug design (Inbathamizh \& Padmini, 2011).

Macrophages (Kupffer cells) play an essential role in the anti-inflammatory process as well as in xenobiotic metabolism (Mahajna et al., 2015). The binding complex of LPS to the cluster of differentiation (CD) 14 protein triggers a signal cascade involving a nuclear factor to enhance the expression of inflammation-related genes (Guo, Sakulnarmrat, \& Konczak, 2014). In general, the results presented in Table 5, showed that the studied plant extracts, effectively reduced the expression of ant-inflammatory enzymes iNOS in LPS-activated murine macrophages, and this reduction was accompanied by the decrease of the nitric oxide (NO) levels (lower $\mathrm{EC}_{50}$ values). To verify whether the reduction of the decrease of NO production, was measured employing the Griess reagent system kit. Among both extracts, the hydroethanolic showed the highest inhibitory effects in NO production by LPS-stimulated RAW264.7 cells $\left(\mathrm{EC}_{50}=251 \mu \mathrm{g} / \mathrm{mL}\right.$ for $A$. leucotrichus and $294 \mu \mathrm{g} / \mathrm{mL}$ for $M$. oleifera), while $M$. oleifera leaves decoction was less active $(321 \mu \mathrm{g} / \mathrm{mL})$, and $A$. leucotrichus decoction did not revealed anti- inflammatory activity. Several authors (Catarino, Talhi, Rabahi, Silva, \& Cardoso, 2016; Sobral et al., 2016) reported that plant phenolic compounds act as anti-inflammatory molecules by different levels of inhibitory action in the LPS-induced NO production. The polyphenols that have a higher number of hydroxyl groups (Gardi et al., 2015), such as the ones identified in this study, are probably the activators of NOproduction inhibition. Moreover, a hydromethanol extract $(70: 30, \mathrm{v} / \mathrm{v})$ of $M$. oleifera leaves collected from sub-Saharan Africa was found to exhibit an anti-inflammatory activity (Coppin et al., 2013). According to these authors, the main molecules detected in the extract were flavonoid glycosides, especially quercetin and kaempferol glycoside derivatives, being related to the anti-inflammatory activity revealed by the extract. Likewise, Upadhyay et al. (2015) also reported anti-inflammatory activity using a crude ethanolic extract of $M$. oleifera dried seeds, finding an excellent inflammation inhibition. These authors used a carrageenan induced inflammation in the hind paw edema of mice, and the extract revealed $85 \%$ inhibition at a dose of $3 \mathrm{mg} / \mathrm{kg}$ of body weight. Moreover, the same effeteness was noted for the infusions extract of flowers, leaves, roots, and bark, and the seeds, showing an antiinflammatory and diuretic activity at a concentration of $1000 \mathrm{mg} / \mathrm{kg}$ of body weight. To the author's best knowledge, the cytotoxicity and antiinflammatory activity of $A$. leucotrichus has not been previously studied.

Certain established drugs have become less effective against many infections agents (Gupta et al., 2017), and antibiotic resistance becomes an alarming issue, which turns the discovery of new active antibacterial agents a ground breaking research (Stojković et al., 2013). The decoction and hydroethanolic preparations of A. leucotrichus and M. oleifera were evaluated for their antibacterial potential against multi-resistant pathogenic strains (Table 6), such as Gram-positive bacteria (E. faecalis, L. monocytogenes, S. aureus) and Gram-negative bacteria (E. coli, $K$. pneumoniae, $M$. morganii, $P$. mirabilis and $P$. aeruginosa). The results shown in Table 6 , indicate that the extracts were moderately active against both Gram-negative and Gram-positive bacteria, being the later more sensible to both plant extracts. In general, the hydroethanolic extracts were more effective than the decoction extracts. $M$. oleifera hydroethanolic extract showed a good antibacterial activity, especially against $S$. aureus (MIC $=0.625 \mathrm{mg} / \mathrm{mL}$ ) and L. monocytogenes (MIC $=2.5 \mathrm{mg} / \mathrm{mL}$ ). As mentioned above, $M$. oleifera decoction showed to be relatively less active against the studied bacteria. Likewise, A. leucotrichus hydroethanolic extract revealed lower MIC values than the decoctions. However, both extracts obtained from the plant had no effect on $P$. mirabilis and very low effect on $K$. pneumoniae, even at the highest concentration tested $(20 \mathrm{mg} / \mathrm{mL})$. The differences observed between the Gram-negative and Gram-positive bacteria response could be due to cell membrane permeability or either to the genetic factors, 
the outer membrane of the Gram-negative bacteria acts as a barrier to many environmental substances including antibiotics (Gyawali \& Ibrahim, 2014). MBC values were not obtained for any of the plant extracts tested (values $>20 \mu \mathrm{g} / \mathrm{mL}$ ).

Several extracts of A. leucotrichus fruits using different solvents (methanol, ethanol, butanol, dimethyl ether and dichloromethane) from Béchar-Algeria were evaluated for their antimicrobial activity against eight bacterial strains and three human pathogenic fungi, revealing an interesting antimicrobial profile (Sebaa et al., 2018).

Also, the antimicrobial activity of a petroleum ether extract obtained from $M$. oleifera leaves from India, was tested against pathogenic bacteria and showed a maximum inhibition of $P$. aeruginosa, followed by $P$. vulgaris, and B. subtilis (Anupama, Pranay, Varma, \& Kumar, 2013). Moreover, the same authors observed a maximum inhibition for E. coli with the chloroform extract, which had comparable results to Gentamycin. The antimicrobial activity of the aqueous extract from $M$. oleifera seeds, was also investigated against several bacterial stains, where the 4( $\alpha$-L-rhamnosyloxy) benzyl isothiocyanate was identified to act on several bacteria and fungi, inhibiting the growth of Mycobacterium phlei, Bacillus subtilis, and S. aureus (Goyal et al., 2007).

According to the phenolic compounds composition reported above, flavonoids glycoside derivatives, especially apigenin and quercetin derivatives have been found to be important factors during the bacterial pathogenic process (Gyawali \& Ibrahim, 2014). These compounds may act as antibiotics, due to their ability to complex with the extracellular and soluble proteins, and also with the bacterial cell walls, often leading to their inactivation and loss of function (Cushnie \& Lamb, 2005; Wink, 2015). According to a previous work (Ziani et al., 2018), the location and number of hydroxyl groups on the phenol group, could also be related to the microorganisms growth inhibition, with evidence that with the increase of hydroxylation, the antimicrobial potential is also higher.

\section{Conclusion}

This study aimed to chemically characterize the nutritional value and chemical constituents of two edible plants A. leucotrichus and $M$. oleifera, and further explore two types of extracts (hydroethanolic and decoctions) regarding their phenolic composition and bioactive potential in terms of cytotoxicity, anti-inflammatory, and antibacterial activities. High levels of proteins, soluble sugars (glucose, fructose and sucrose), PUFA ( $\alpha$-linoleic, oleic and linoleic acids) and ashes were present in both plants, indicating that these species could be included in the daily diet as sources of nutrients. The chromatographic analyses showed that both plants are sources of bioactive compounds, especially with the identification of luteolin-O-(malonyl-glucoside) as the main compound in A. leucotrichus, and quercetin-3-O-(6"-malonyl-glucoside) and 3-O-caffeoylquininc acid in $M$. oleifera. The presence of these phenolic compounds in both plant species gave insight into understanding the significant pharmacological properties that were demonstrated, especially by the hydroethanolic extracts, which seemed to be more active against the tested tumor cell lines and murine macrophages RAW 264.7 NO production, and inhibited the growth of clinical MDR bacteria. Thus, these species could be proposed as new food ingredients with nutraceutical and functional properties, validating the medicinal principle behind the ethnobotanical practices associated to these plant species.

However, it is worthwhile to further investigate in-vivo biological effects, in order to identify the most promising extracts and to isolate the active compounds.

\section{Ethic statement}

This statement declares that the manuscript entitled "Detailed chemical composition and functional properties of Ammodaucus leucotrichus Cross. \& Dur. and Moringa oleifera Lamarck", does not involve the use of human subjects and animal experiments.

\section{Conflict of interest}

The authors declared that there is no conflict of interest.

\section{Acknowledgements}

The authors are grateful to the Foundation for Science and Technology (FCT, Portugal) and FEDER under Programme PT2020 for financial support to CIMO (UID/AGR/00690/2013), L. Barros and R.M. Calhelha contract. The authors are also grateful to the Interreg EspañaPortugal for financial support through the project 0377_Iberphenol_6_E.

\section{References}

Amabye, T. G. (2016). Chemical compositions and nutritional value of Moringa oleifera available in the market of Mekelle. Journal of Food and Nutrition Sciences, 3(5), 187-190. https://doi.org/10.11648/j.jfns.20150305.14.

Amaglo, N. K., Bennett, R. N., Lo Curto, R. B., Rosa, E. A. S., Lo Turco, V., Giuffrida, A., ... Timpo, G. M. (2010). Profiling selected phytochemicals and nutrients in different tissues of the multipurpose tree Moringa oleifera L., grown in Ghana. Food Chemistry, 122(4), 1047-1054. https://doi.org/10.1016/j.foodchem.2010.03.073.

Anupama, P., Pranay, P. P., Varma, M. C., \& Kumar, K. (2013). Evaluation of the antibacterial potential of Moringa oleifera and Azadirachta indica against some pathogenic microbes: A comparative study. International Journal of Drug Development and Research, 5(1), 214-218.

Anwar, F., Latif, S., Ashraf, M., \& Gilani, A. H. (2007). Moringa oleifera: A food plant with multiple medicinal uses. Phytotherapy Research, 21, 17-25. https://doi.org/10.1002/ ptr.2023.

AOAC (2016). The Association of Official Analytical Chemists International. Official Methods of Analysis, 38(8), 431.

Arbex, A. K., Bizarro, V. R., Santos, J. C. S., Araújo, L. M. M., De Jesus, A. L. C., Fernandes, M. S. A., ... Marcadenti, A. (2015). The impact of the essential fatty acids (EFA) in human health. Open Journal of Endocrine and Metabolic Diseases, 5, 98-104.

Asante, W. J., Nasare, I. L., Tom-dery, D., \& Ochire-boadu, K. (2014). Nutrient composition of Moringa oleifera leaves from two agro ecological zones in Ghana. African Journal of Plant Science, 8(1), 65-71. https://doi.org/10.5897/AJPS2012.0727.

Barros, L., Morales, P., Sanchez-Mata, M. C., Oliveira, M. B. P. P., \& Ferreira, I. C. F. R. (2015). Nutritional parameters of infusions and decoctions obtained from Fragaria vesca L. roots and vegetative parts. LWT - Food Science and Technology, 62, 32-38. https://doi.org/10.1016/j.lwt.2015.01.034.

Barros, L., Pereira, E., Calhelha, R. C., Carvalho, A. M., Santos-buelga, C., \& Ferreira, I. C. F. R. (2013). Bioactivity and chemical characterization in hydrophilic and lipophilic compounds of Chenopodium ambrosioides L. Journal of Functional Foods, 5, 1732-1740. https://doi.org/10.1016/j.jff.2013.07.019.

Benarba, B. (2016). Medicinal plants used by traditional healers from South-West Algeria : An ethnobotanical study. Journal of Intercultural Ethnopharmacology, 5(4), 320-330. https://doi.org/10.5455/jice.20160814115725.

Bennett, R. N., Mellon, F. A., Foidl, N., Pratt, J. H., Dupont, S. M., Perkins, L., \& Kroon, P. A. (2003). Profiling Glucosinolates and phenolics in vegetative and reproductive tissues of the multi-purpose trees Moringa oleifera L. (Horseradish Tree) and Moringa stenopetala L. Journal of Agricultural and Food Chemistry, 51, 3546-3553.

Bessada, S. M. F., Barreira, J. C. M., Barros, L., Ferreira, I. C. F. R., \& Oliveira, M. B. P. P. (2016). Phenolic profile and antioxidant activity of Coleostephus myconis (L.) Rchb.f.: An underexploited and highly disseminated species. Industrial Crops and Products, 89, 45-51. https://doi.org/10.1016/j.indcrop.2016.04.065.

Boukandoul, S., Casal, S., Cruz, R., Pinho, C., \& Zaidi, F. (2017). Algerian Moringa oleifera whole seeds and kernels oils: characterization, oxidative stability and antioxidant capacity. European Journal of Lipid Science and Technology, 119, 1600410. https://doi. org/10.1002/ejlt.201600410.

Carocho, M., \& Ferreira, I. C. F. R. (2013). The role of phenolic compounds in the fight against cancer - A review. Anti-Cancer Agents in Medicinal Chemistry, 13, 1236-1258. https://doi.org/10.2174/18715206113139990301.

Catarino, M. D., Talhi, O., Rabahi, A., Silva, A. M. S., \& Cardoso, S. M. (2016). The antiinflammatory potential of flavonoids: Mechanistic aspects. Studies in natural products chemistry: 1st ed., Vol. 48, (pp. 65-99). Elsevier B.V.. https://doi.org/10.1016/B9780-444-63602-7.00003-5.

Clifford, M. N., Johnston, K. L., Knight, S., \& Kuhnert, N. (2003). Hierarchical scheme for LC-MSn identification of chlorogenic acids. Journal of Agricultural and Food Chemistry, 51, 2900-2911.

Coppin, J. P., Xu, Y., Chen, H., Pan, M., Ho, C., Simon, J. E., \& Wu, Q. (2013). Determination of flavonoids by LC/MS and anti-inflammatory activity in Moringa oleifera. Journal of Functional Foods, 5, 1892-1899. https://doi.org/10.1016/j.jff. 2013.09.010.

Cushnie, T. P. T., \& Lamb, A. J. (2005). Antimicrobial activity of flavonoids. International Journal of Antimicrobial Agents, 26, 343-356. https://doi.org/10.1016/j.ijantimicag. 2005.09.002.

David, O. M., Ogunmoroti, O., Ajayi, O. O., Eleyode, V., Ogunniran, A., Adegbuyi, T. A., \& Famurewa, O. (2017). A Review of biological and therapeutic activities of Moringa oleifera Linn. Journal of Modern Drug Discovery and Drug Delivery Research, 4(3), 1-13. 
Dias, M. I., Barros, L., Morales, P., Cámara, M., Alves, M. J., Oliveira, M. B. P. P., ... Ferreira, I. C. F. R. (2016). Wild Fragaria vesca L. fruits: a rich source of bioactive phytochemicals. Food and Function, 7(11), 4523-4532. https://doi.org/10.1039/ C6FO01042C.

Edwinanto, L., Septiadi, E., Nurfazriah, L. R., Anastasya, K. S., \& Pranata, N. (2018). Phytochemical features of Moringa oleifera leaves as anticancer a Review article. Journal of Medicine and Health, 2(1), 680-688.

El Haci, A. I., Mazari, W., Gherib, M., \& Atik Bekkara, F. (2018). Evaluation of the antioxidant activities of organic extracts from Ammodaucus leucotrichus Coss \& Dur fruit part harvested from the Algerian Sahara. Advances in Complementary and Alternative Medicine, 1(1), 1-5.

Gardi, C., Bauerova, K., Stringa, B., Kuncirova, V., Slovak, L., Ponist, S., ... Russo, G. L. (2015). Quercetin reduced inflammation and increased antioxidant defense in rat adjuvant arthritis. Archives of Biochemistry and Biophysics, 583, 150-157. https://doi. org/10.1016/j.abb.2015.08.008.

Gherraf, N., Zellagui, A., Kabouche, A., Lahouel, M., Salhi, R., \& Rhouati, S. (2017). Chemical constituents and antimicrobial activity of essential oils of Ammodaucus leucotricus. Arabian Journal of Chemistry, 10, S2476-S2478. https://doi.org/10.1016/ j.arabjc.2013.09.013.

Gopalakrishnan, L., Doriya, K., \& Santhosh, D. (2016). Moringa oleifera: A review on nutritive importance and its medicinal application. Food Science and Human Wellness, 5(2), 49-56. https://doi.org/10.1016/j.fshw.2016.04.001.

Goyal, B. R., Agrawal, B. B., Goyal, R. K., \& Mehta, A. A. (2007). Phyto-pharmacology of Moringa oleifera Lam. ó An overview. Natural Product Radiance, 6(4), 347-353.

Guo, Y., Sakulnarmrat, K., \& Konczak, I. (2014). Anti-inflammatory potential of native Australian herbs polyphenols. Toxicology Reports, 1, 385-390. https://doi.org/10. 1016/j.toxrep.2014.06.011.

Gupta, R. C., Chang, D., Nammi, S., Bensoussan, A., Bilinski, K., \& Roufogalis, B. D. (2017). Interactions between antidiabetic drugs and herbs: an overview of mechanisms of action and clinical implications. Diabetology \& Metabolic Syndrome, 9(59), 1-12. https://doi.org/10.1186/s13098-017-0254-9.

Gyawali, R., \& Ibrahim, S. A. (2014). Natural products as antimicrobial agents. Food Control, 46, 412-429. https://doi.org/10.1016/j.foodcont.2014.05.047.

Halla, N., Boucherit, K., Boucherit-otmani, Z., Zohra, F., \& Rahmani, N. (2018a). Ammodaucus leucotrichus and Citrullus colocynthis from Algerian Sahara: Ethnopharmacological application, phytochemical screening, polyphenols content and antioxidant activity of hydromethanolic extracts. Journal of King Saud University Science. https://doi.org/10.1016/j.jksus.2018.03.018.

Halla, N., Heleno, S. A., Costa, P., Fernandes, I. P., Calhelha, R. C., Boucherit, K., ... Barreiro, F. (2018b). Chemical profile and bioactive properties of the essential oil isolated from Ammodaucus leucotrichus fruits growing in Sahara and its evaluation as a cosmeceutical ingredient. Industrial Crops and Products, 119, 249-254. https://doi. org/10.1016/j.indcrop.2018.04.043.

Inbathamizh, L., \& Padmini, E. (2011). Insilico studies on the enhancing effect of anticancer phytochemicals of Moringa oleifera on cellular prostatic acid phosphatase activity. Drug Invent Today, 3, 186-192.

Kane, F. C., Tounkara, L. S., Kimassoum, D., Guewo-Fokeng, M., Diop, A. T., \& Mbacham, W. F. (2017). Nutritional value of a dietary supplement of Moringa oleifera and Pleurotus ostreatus. African Journal of Food Science, 11(6), 171-177. https://doi.org/ 10.5897/AJFS2016.1545.

Karthivashan, G., Arulselvan, P., Alimon, A. R., Ismail, I. S., \& Fakurazi, S. (2015). Competing role of bioactive constituents in Moringa oleifera extract and conventional nutrition feed on the performance of cobb 500 broilers. BioMed Research International, 2015, 1-13.

Karthivashan, G., Fard, M. T., Arulselvan, P., Abas, F., \& Fakurazi, S. (2013). Identification of bioactive candidate compounds responsible for oxidative challenge from hydro-ethanolic extract of Moringa oleifera Leaves. Journal of Food Science, 78(9), C1368-C1375. https://doi.org/10.1111/1750-3841.12233.

Kmail, A., Lyoussi, B., Zaid, H., \& Saad, B. (2015). In vitro assessments of cytotoxic and cytostatic effects of Asparagus aphyllus, Crataegus aronia, and Ephedra alata in monocultures and Co-cultures of Hepg2 and THP-1-derived macrophages. Pharmacognosy Communications, 5(3), 165-172. https://doi.org/10.5530/pc.2015. 3.2 .

Louail, Z., Kameli, A., Benabdelkader, T., Bouti, K., Hamza, K., \& Krimat, S. (2016). Antimicrobial and antioxidant activity of essential oil of Ammodaucus leucotrichusCoss. \& Dur. seeds. Journal of Materials and Environmental Science, 7(7), 2328-2334.

Mahajna, S., Azab, M., Zaid, H., Farich, B. A., Battah, F. Al, Mashner, S., \& Saad, B. (2015). In vitro evaluations of cytotoxicity and anti-inflammatory effects of Peganum harmala seed extracts in THP-1-derived macrophages. European Journal of Medicinal Plants, 5(2), 016. https://doi.org/10.9734/EJMP/2015/13267.

Makita, C., Chimuka, L., Cukrowska, E., Steenkamp, P. A., Kandawa-Schutz, M., Ndhlala, A. R., \& Madala, N. E. (2017). UPLC-qTOF-MS profiling of pharmacologically important chlorogenic acids and associated glycosides in Moringa ovalifolia leaf extracts. South African Journal of Botany, 108, 193-199. https://doi.org/10.1016/j.sajb.2016. 10.016.

Makita, C., Chimuka, L., Steenkamp, P., Cukrowska, E., \& Madala, E. (2016). Comparative analyses of flavonoid content in Moringa oleifera and Moringa ovalifolia with the aid of UHPLC-qTOF-MS fingerprinting. South African Journal of Botany, 105, 116-122. https://doi.org/10.1016/j.sajb.2015.12.007.

Maryann, C. U., Lord, A., Uchechukwu, N., \& Chibuike, C. U. (2018). Potential of Moringa oleifera seeds and leaves as functional food ingredients for human health promotion. Journal of Food and Nutrition Research, 57(1), 1-14.
Abas, F., Khatib, A., Shaari, K., \& Lajis, N. H. (2014). Chemical characterization and antioxidant activity of three medicinal Apiaceae species. Industrial Crops and Products, 55, 238-247. https://doi.org/10.1016/j.indcrop.2014.02.013.

Moyo, B., Masika, P. J., Hugo, A., \& Muchenje, V. (2011). Nutritional characterization of Moringa (Moringa oleifera Lam.) leaves. African Journal of Biotechnology, 10(60), 12925-12933. https://doi.org/10.5897/AJB10.1599.

Nouman, W., Anwar, F., Gull, T., Newton, A., \& Rosa, E. (2016). Profiling of polyphenolics, nutrients and antioxidant potential of germplasm's leaves from seven cultivars of Moringa oleifera Lam. Industrial Crops \& Products, 83, 166-176. https:// doi.org/10.1016/j.indcrop.2015.12.032.

Oduro, I., Ellis, W. O., \& Owusu, D. (2008). Nutritional potential of two leafy vegetables: Moringa oleifera and Ipomoea batatas leaves. Scientific Research and Essay, 3(2), 57-60.

Oyeyinka, A. T., \& Oyeyinka, S. A. (2016). Moringa oleifera as a food fortificant : Recent trends and prospects. Journal of the Saudi Society of Agricultural Sciences. https://doi. org/10.1016/j.jssas.2016.02.002.

Pires, T. C. S. P., Dias, M. I., Barros, L., Alves, M. J., Oliveira, M. B. P. P., Santos-Buelga, C., \& Ferreira, I. C. F. R. (2018). Antioxidant and antimicrobial properties of dried Portuguese apple variety (Malus domestica Borkh. cv Bravo de Esmolfe). Food Chemistry, 240, 701-706. https://doi.org/10.1016/j.foodchem.2017.08.010.

Pires, T. C. S. P., Dias, M. I., Barros, L., \& Ferreira, I. C. F. R. (2017). Nutritional and chemical characterization of edible petals and corresponding infusions: Valorization as new food ingredients. Food Chemistry, 220, 337-343. https://doi.org/10.1016/j foodchem.2016.10.026.

Purwal, L., Pathak, A., \& Jain, U. (2010). In vivo anticancer activity of the leaves and fruits of Moringa oleifera on mouse melanoma. Pharmacologyonline, 1, 655-665.

Quezel, P., \& Santa, S. (1963). Nouvelle flore de l'Algérie et des régions désertiques méridionales. Nouvelle flore de l'Algérie et des régions désertiques méridionales: Vol. Tome II, (pp. 350-1170). Paris: CNRS.

Sánchez-Machado, D. I., Lopez-Cervantes, J., \& Rios Vazquez, N. J. (2006). High-performance liquid chromatography method to measure $\alpha$ - and $\mathrm{y}$-tocopherol in leaves, flowers and fresh beans from Moringa oleifera. Journal of Chromatography A, 1105, 111-114. https://doi.org/10.1016/j.chroma.2005.07.048.

Sánchez-Machado, D. I., Núñez-gastélum, J. A., \& Reyes-moreno, C. (2009). Nutritional quality of edible parts of Moringa oleifera. Food Analytical Methods, 3(3), 175-180. https://doi.org/10.1007/s12161-009-9106-z.

Sebaa, A., Marouf, A., Kambouche, N., \& Derdour, A. (2018). Phytochemical composition, antioxidant and antimicrobial activities of Ammodaucus leucotrichus fruit from Algerian Sahara. Oriental Journal of Chemistry, 34(1), 519-525.

Shahidi, F., \& Ambigaipalan, P. (2015). Phenolics and polyphenolics in foods, beverages and spices: Antioxidant activity and health effects - A review. Journal of Functional Foods, 18, 820-897. https://doi.org/10.1016/j.jff.2015.06.018.

Sobral, F., Sampaio, A., Falcão, S., Queiroz, M. J. R. P., Calhelha, R. C., Vilas-Boas, M., \& Ferreira, I. C. F. R. (2016). Chemical characterization, antioxidant, anti-inflammatory and cytotoxic properties of bee venom collected in Northeast Portugal. Food and Chemical Toxicology, 94, 172-177. https://doi.org/10.1016/j.fct.2016.06.008.

Son, H. Le, \& Anh, N. P. (2013). Phytochemical composition, in vitro antioxidant and anticancer activities of quercetin from methanol extract of Asparagus cochinchinensis (LOUR.)Merr. tuber. Journal of Medicinal Plants Research, 7(46), 3360-3366. https:// doi.org/10.5897/JMPR2013.5257.

Sreelatha, S., \& Padma, P. (2011). Modulatory effects of Moringa oleifera extracts against hydrogen peroxide-induced cytotoxicity and oxidative damage. Human and Experimental Toxicology, 30, 1359-1368.

Stadtlander, T., \& Becker, K. (2017). Proximate composition, amino and fatty acid profiles and element compositions of four different Moringa species. Journal of Agricultural Science, 9(7), 46-57. https://doi.org/10.5539/jas.v9n7p46.

Stojković, D., Petrović, J., Soković, M., Glamočlija, J., Kukić-Marković, J., \& Petrović, S. (2013). In situ antioxidant and antimicrobial activities of naturally occurring caffeic acid, p-coumaric acid and rutin, using food systems. Journal of the Science of Food and Agriculture, 93(13), 3205-3208. https://doi.org/10.1002/jsfa.6156.

Tiloke, C., Phulukdaree, A., \& Chuturgoon, A. A. (2013). The antiproliferative effect of Moringa oleifera crude aqueous leaf extract on cancerous human alveolar epithelial cells. BMC Complementary and Alternative Medecine, 13(226), 1-8.

Upadhyay, P., Yadav, M., Mishra, S., Sharma, P., \& Purohit, S. (2015). Moringa oleifera: A review of the medical evidence for its nutritional and pharmacological properties. International Journal of Research in Pharmacy and Science, 5(2), 12-16.

Vadhana, P., Singh, B. R., Bharadwaj, M., \& Singh, S. V. (2015). Emergence of herbal antimicrobial drug resistance in clinical bacterial isolates. Pharmaceutica Analytica Acta, 6(10), 434. https://doi.org/10.4172/21532435.1000434.

Wink, M. (2015). Modes of action of herbal medicines and plant secondary metabolites. Medicines, 251-286. https://doi.org/10.3390/medicines2030251.

Witt, K. A. (2013). The nutrient content of Moringa oleifera leaves. ECHO Research Note, 1(1), 10-20.

Yaméogo, charles, W., Bengaly, M. D., Savadogo, A., Nikiema, P. A., \& Traore, S. A. (2011). Determination of chemical composition and nutritional values of Moringa oleifera leaves. Pakistan Journal of Nutrition, 10(3), 264-268.

Ziani, B. E. C., Barros, L., Boumehira, A. Z., Bachari, K., Heleno, S. A., Alves, M. J., \& Ferreira, I. C. F. R. (2018). Profiling polyphenol composition by HPLC-DAD-ESI/MSn and the antibacterial activity of infusion preparations obtained from four medicinal plants. Food and Function, 9, 149-159. https://doi.org/10.1039/C7FO01315A.

Ziani, B. E. C., Calhelha, R. C., Barreira, J. C. M., Barros, L., Hazzit, M., \& Ferreira, I. C. F. R. (2015). Bioactive properties of medicinal plants from the Algerian flora: Selecting the species with the highest potential in view of application purposes. Industrial Crops and Products, 77, 582-589. https://doi.org/10.1016/j.indcrop.2015.09.034. 